RESEARCH PAPER RP1649

Part of Journal of Research of the National Bureau of Standards, Volume 34. April 1945

\title{
MELTING POINT OF ALPHA-ALUMINA
}

\author{
By R. F. Geller and P. J. Yavorsky
}

\section{ABSTRACT}

Results are given of seven melting-point determinations on alpha-alumina of high purity in an oxidizing atmosphere and under atmospheric pressure. There was detectable contamination of the specimens by vapors of other elements in the furnace atmosphere, but the results are believed to show that the melting point of alpha-alumina is within the range $2,000^{\circ}$ to $2,030^{\circ} \mathrm{C}$.

\section{CONTENTS}

I. Introduction

II. Previous determinations

III. Materials _._.

IV. Temperature measurements _ _ _

V. Method

VI. Results

VII. Conclusion

\section{INTRODUCTION}

In the determination of a value for the temperature at which an element or compound melts, or freezes, the value obtained depends not only upon the purity of the material, the method, and the skill employed, but also on the temperature scale on which the value is expressed. Prior to the adoption of the International Temperature Scale ${ }^{1}$ in 1927 , there was no scale in general use, particularly for high temperatures, and in many cases the differences between values reported for the same temperature are attributable at least in part to differences in the temperature scales used. Consequently, one must take into account the scale used by an investigator when his reported values are compared with values previously reported. This is especially important for values determined prior to 1927. In some cases, sufficient data are available to permit expressing such values on the present International Temperature Scale, but in others the available information, or the method used, does not make this possible.

In all the observations of the melting point of alpha-alumina $\left(\mathrm{Al}_{2} \mathrm{O}_{3}\right)$ that have come to our attention, an optical pyrometer was employed to measure the temperature. The pyrometers were calibrated at the melting, or freezing, point of one or more metals (or compared with an optical pyrometer that had been so calibrated) and an

1 George K. Burgess, BS J. Research 1, 635 (1928) RP22. 
equation of some form applied for extrapolating to the melting point of $\mathrm{Al}_{2} \mathrm{O}_{3}$. The different melting, or freezing, points at which the pyrometers were calibrated, the different values assigned to these points, and the equations used for extrapolating, constitute the differences in the temperature scales referred to above.

For any given sample of alumina, the temperature at which it melts will depend not only upon the initial purity but also upon the kind and amount of impurity "picked up" from the furnace atmosphere and the specimen support. In most of the previous reports on the melting point of alumina, some reference was made to the initial purity, but no attempt was made after the test to determine the purity at the time the specimen melted.

\section{PREVIOUS DETERMINATIONS}

The value usually given in the literature for the melting point of alpha- $\mathrm{Al}_{2} \mathrm{O}_{3}$ is $2,050^{\circ} \mathrm{C}$ as determined by Kanolt, ${ }^{2}$ who calibrated his optical pyrometer at the melting points of antimony, silver, copper, and diopside. As a check on his pyrometric apparatus as a whole, he determined the melting point of platinum, to which he assigned the value $1,755^{\circ} \mathrm{C}$. However, he did not heat the platinum by the same method or in the same furnace as he did the $\mathrm{Al}_{2} \mathrm{O}_{3}$. Consequently, any correction of his reported values to the International Temperature Scale would be spurious.

Three years earlier, Ruff and Goecke ${ }^{3}$ had reported the value $2,020^{\circ}$ $\mathrm{C}$ for the melting point of $\mathrm{Al}_{2} \mathrm{O}_{3}$. This was determined in a graphite resistance furnace and in nitrogen under atmospheric pressure, but the purity of the specimens, which rested on $\mathrm{Al}_{2} \mathrm{O}_{3}$, was not indicated. Their optical pyrometers, of which they used one for viewing the specimen through the side of the furnace and the other from the top, were calibrated by observing the melting of gold and of platinum in the same furnace. In their calculations they used $1,071^{\circ} \mathrm{C}$ for the melting point of gold and $1,757^{\circ} \mathrm{C}$ for platinum. When the $\mathrm{Al}_{2} \mathrm{O}_{3}$ was heated under reduced pressure $(6 \mathrm{~mm} \mathrm{Hg})$, they noted lively vaporization at $1,740^{\circ} \mathrm{C}$.

In 1916 Ruff and Lauschke, ${ }^{4}$ also using a graphite resistance furnace and reduced pressure $(7.5$ and $7.7 \mathrm{~mm} \mathrm{Hg})$, reported observing the melting of $\mathrm{Al}_{2} \mathrm{O}_{3}$ at $2,008^{\circ} \mathrm{C}$ and $2,005^{\circ} \mathrm{C}$, respectively. Their opticalpyrometer calibration was based on the melting point of gold with an assigned value of $1,062.4^{\circ} \mathrm{C}$, and on $1.437 \mathrm{~cm}$-degrees centigrade for the constant $\mathrm{C}_{2}$ in Wien's formula. ${ }^{5}$ These melting-point values for $\mathrm{Al}_{2} \mathrm{O}_{3}$ correspond to about $2,020^{\circ} \mathrm{C}$ and $2,017^{\circ} \mathrm{C}$, respectively, when recalculated on the basis of $1,063^{\circ} \mathrm{C}$ for the gold point and 1.432 for $\mathrm{C}_{2}$. The $\mathrm{Al}_{2} \mathrm{O}_{3}$ was described as a white powder with an ignition loss of 3.5 percent, indicating that it was prepared from a salt and that it was probably of high purity. Their heating rates were 48 and 67 degrees centigrade a minute.

In 1931 Weigel and Kaysser, ${ }^{6}$ published the results of what appears to have been a carefully conducted series of melting-point determinations, but here again the purity of the $\mathrm{Al}_{2} \mathrm{O}_{3}$ was only implied. Their

2 C. W. Kanolt, Bul. BS 10, 295 (1914) \$212.

3 Otto Ruff and Otto Goecke, Z. angew. Chem. 242, 1459 (1911).

4 Otto Ruff and George Lauschke, Z., anorg. allgem. Chem. 97, 73 (1916).

5 H. T. Wensel, J. Applied Phys. 11, 373 (1940).

6 O. Weigel and F. Kaysser, Neues Jahrb. Mineral. Geol. Beil. 64 [A], 321 (1931), 
synthetic corundum was a massive crystalline material furnished by I. G. Farbenindustrie, and the powdered samples were described as the purest Kahlbaum preparations of $\mathrm{Al}_{2} \mathrm{O}_{3}$ for reagent purposes, and of alkali-free hydroxide. The furnace was of the graphite resistance type, with a $\mathrm{ZrO}_{2}$ inner lining through which either $\mathrm{N}_{2}$, or air, could be passed as desired. The calibration of the optical pyrometer was based on $1,063^{\circ} \mathrm{C}$ for the melting point of gold and on the value 1.430 for the constant $\mathrm{C}_{2}$. The calibration and melting-point technic was checked by observing the melting of silver, gold, palladium, platinum, rhodium, and iridium. Of immediate interest is their accepted value of $1,770^{\circ} \mathrm{C}$ for platinum, which is in good agreement with the value of $1,773.5^{\circ} \mathrm{C}$ for this point on the International Temperature Scale.

In 34 tests, specimens of the corundum were fused on charcoal in a nitrogen atmosphere, and at a heating rate which ranged from 5 to 20 degrees centigrade a minute. The melting-point values ranged from $1,990^{\circ}$ to $2,037^{\circ} \mathrm{C}$, with a mean of $2,007^{\circ} \pm 4^{\circ} \mathrm{C}$. For a single determination with the specimen on iridium and in a stream of air, melting was observed at $2,001^{\circ} \mathrm{C}$; the tested specimen was described as water clear. The average of 40 tests on the powders was $2,001^{\circ}$ $\pm 4^{\circ} \mathrm{C}$, using charcoal as the support for the specimens (which had been formed by pressing, with gum tragacanth as the binder) and an atmosphere of nitrogen. No difference in results was noted for the oxide and the hydroxide. Weigel and Kaysser also determined the melting point of the $\mathrm{Al}_{2} \mathrm{O}_{3}$ powder in air and on iridium. For these tests, a small piece of rhodium wire was placed upon the alumina specimen and in two trials the $\mathrm{Al}_{2} \mathrm{O}_{3}$ was observed to melt 35 and 40 degrees centigrade respectively, above the melting temperature for the rhodium. Accepting $1,966^{\circ} 7$ as the melting point of rhodium on the International Temperature Scale places the melting of the alumina at $2,001^{\circ} \mathrm{C}$ in the first test and at $2,006^{\circ} \mathrm{C}$ in the second. If the weighted average of all of their values is recalculated to the International Temperature Scale, we obtain $2,000^{\circ} \mathrm{C}$.

Weigel and Kaysser also conducted several tests with colorless natural sapphire from Ceylon and with bluish and greenish natural corundum from Australia. It is interesting that they obtained higher values for these specimens-2,022 $\pm 9^{\circ} \mathrm{C}$ for the former and $2,021^{\circ}$ $\pm 4^{\circ} \mathrm{C}$ for the latter.

Bunting ${ }^{8}$ reported the melting of $\mathrm{Al}_{2} \mathrm{O}_{3}$ at $2,040^{\circ} \mathrm{C}$ and at $2,045^{\circ} \mathrm{C}$. His optical pyrometer was calibrated at the National Bureau of Standards, and his values are expressed on the international scale. The oxide was prepared by dissolving aluminum of 99.95 percent purity in reagent quality $\mathrm{HNO}_{3}$, and igniting at $1,400^{\circ} \mathrm{C}$. All reactions were carried out in platinum. The granules of sintered alumina were placed in a well (about $7 \mathrm{~mm}$ deep by $4 \mathrm{~mm}$ in diameter) formed in the top of an iridium pellet, which was then heated by induction in air and under atmospheric pressure. The temperature was raised quickly to about $2,000^{\circ} \mathrm{C}$ and then increased at 5 to 10 degrees centigrade a minute, until the specimen of $\mathrm{Al}_{2} \mathrm{O}_{3}$ was seen to melt. The pyrometer was sighted on the iridium.

7 Wm. F. Roeser and H. T. Wensel, BS J. Research 12, 519 (1934) RP676.

8 E. N. Bunting, BS J. Research 5, 325 (1930) RP203; 6, 947 (1931) RP317. 
In 1943 Geller and Bunting ${ }^{9}$ reported the value $2,035^{\circ} \mathrm{C}$ for the melting point of $\mathrm{Al}_{2} \mathrm{O}_{3}$. They used the same pyrometer previously used by Bunting (see footnote 8), but fragments of the $\mathrm{Al}_{2} \mathrm{O}_{3}$ were placed upon iridium (fig. 1), the pyrometer was sighted directly on the specimen, and the furnace was heated with $\mathrm{ThO}_{2}-\mathrm{CeO}_{2}$ resistors. ${ }^{10}$ This value of $2,035^{\circ} \mathrm{C}$ represented seven determinations ranging from $2,000^{\circ}$ to $2,040^{\circ} \mathrm{C}$, and the alumina was believed to be at least 99.9 percent pure.

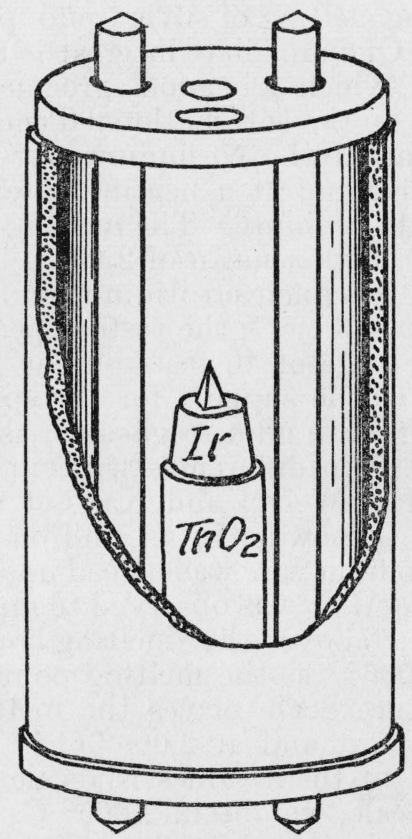

FIGURE 1.-Furnace setup for melting-point tests.

Cut-away section of the heating chamber in the furnace described in J. Research NBS 27,555 (1941) RP1443* The chamber was made of thoria, and the resistors, of which two are shown in place, were made of 85 percent thoria and 15 percent ceria. The pyramidal-shaped specimen rests on an iridium "button," which is supported by a thoria pedestal.

Because of several factors which, at the time, were not recognized as militating against the accuracy of the results, the authors feel that the value of $2,035^{\circ} \mathrm{C}$ is to be questioned.

As a part of further high-temperature investigations, seven additional determinations were made under conditions considered to be productive of more reliable data, and the results are reported in this paper.

\section{MATERIALS}

Alumina from three sources was used:

Alumina A.- This had been fused and recrystallized by the Norton Co., Worcester, Mass. The sample was submitted by Raymond R. Ridgway, who described it as soda free and containing 0.05 percent

9 R. F. Geller and E. N. Bunting, J. Research NBS 31, 255 (1943) RP1564.

10 R. F. Geller, J. Research NBS 27, 555 (1941) RP1443. 
of included carbon, the balance being $\mathrm{Al}_{2} \mathrm{O}_{3}$. The specimens were irregular fragments of crystals about $3 / 16$ in. in maximum dimension.

Alumina B.-This was obtained from another industrial concern. The specimens were formed by cutting them to the desired shape with a diamond impregnated wheel from a single crystal of synthetic colorless corundum about $1 / 8$ in. in diameter. Spectrographic analysis indicated that it contained about 99.99 percent of $\mathrm{Al}_{2} \mathrm{O}_{3}$, and that the 0.01 percent of impurity was about four-tenths $\mathrm{CaO}$ and about three-tenths $\mathrm{SiO}_{2}$.

Alumina C.-This was prepared by dissolving aluminum of 99.987 percent purity ${ }^{11}$ with reagent quality $\mathrm{HNO}_{3}$ and igniting at $1,100^{\circ} \mathrm{C}$. All reactions were carried out in platinum, and the spectrogram of the sintered oxide indicated less than 0.01 percent each of $\mathrm{Ag}, \mathrm{B}, \mathrm{Ca}$, $\mathrm{Cu}, \mathrm{Fe}, \mathrm{Mg}$, and $\mathrm{Si}$. The specimens, about $3 / 16$ in. in maximum dimension, were irregular fragments of this sintered and porous sample.

\section{TEMPERATURE MEASUREMENTS}

Three Leeds \& Northrup optical pyrometers were used, and all were calibrated at the National Bureau of Standards. They indicated temperatures on the international scale, based on $1,063^{\circ} \mathrm{C}$ as the gold point and $1.432 \mathrm{~cm}$-degrees for the constant $C_{2}$ in the following formula, as presented and discussed by Wensel. ${ }^{12}$

in which

$$
\frac{1}{t+273}=\frac{1}{t_{0}+273}-\frac{\lambda \ln \left(J / J_{0}\right)}{C_{2}},
$$

$t=$ determined temperature, ${ }^{\circ} \mathrm{C}$.

$t_{0}=$ gold point $\left(1,063^{\circ}\right)$.

$J=$ radiant energy of wavelength, $\lambda$, from black body at temperature $t$.

$J_{0}=$ the corresponding value for temperature $t_{0}$.

$\ln =$ natural logarithm.

Pyrometer D.-This was the same instrument used by Bunting (see footnote 8), and later by Geller and Bunting (see footnote 9), except that it had been reconditioned and recalibrated.

Pyrometer E.-This was of recent manufacture, permitting a clearer image of the specimen and more precise tempertature readings than was possible with pyrometer $D$.

Pyrometer F.-This was a new instrument of the same model as pyrometer $E$.

\section{METHOD}

The specimens were heated in air, under atmospheric pressure, and on iridium, using the furnace described by Geller (see footnote 10) and the arrangement shown in figure 1. By careful placement of the iridium "button" so that its flat (or slightly concave) upper surface was perpendicular to the line of vision, an effect was obtained in which the flat iridium surface reflected less light to the pyrometer than did the specimen. As a result, the metal appeared slightly colder than the specimen and made it visible in outline.

11 James I. Hofiman and G. E. F. Lundell, J. Research NBS 18, 1 (1937) RP957.

12 H. T. Wensel, J. Am. Ceram. Soc. 19,81 (1936). 
By using specimens which showed sharp corners in outline, as viewed from above, the beginning of melting could be observed as a dulling, or rounding, of the corners, and the corresponding temperature was obtained by sighting the pyrometer on the specimen.

In order to check the accuracy of the temperature measurements, each pyrometer was used to observe the melting of platinum or of a platinum-rhodium alloy. These observations were made in the same furnace by using pieces of wire which rested on a refractory oxide base in place of the iridium. In this case, the wire could be seen because its surface reflected the colder observation hole and also the slightly hotter heating elements. The pyrometer was sighted on the refractory, for which $\mathrm{ThO}_{2}, \mathrm{ZrO}_{2}$, or $\mathrm{Al}_{2} \mathrm{O}_{3}$ was used. The observations show that black-body conditions were realized and that the over-all inaccuracies of the temperature measurements were within the limits of the optical pyrometer, which was certified to \pm 10 degrees centigrade. The actual values obtained are as follows:

\begin{tabular}{|c|c|c|c|}
\hline $\begin{array}{l}60 \mathrm{Pt}-40 \mathrm{Rh} \\
80 \mathrm{Pt}-20 \mathrm{Rh} \\
90 \mathrm{Pt}-10 \mathrm{Rh} \\
100 \mathrm{Pt}\end{array}$ & $\begin{array}{l}1,925^{\circ} \mathrm{C} \\
1,890^{\circ} \mathrm{C} \\
1,845^{\circ} \mathrm{C} \\
1,776^{\circ} \mathrm{C}\end{array}$ & \begin{tabular}{|c|} 
\\
\end{tabular} & $\begin{array}{l}1,940^{\circ} \pm 20^{\circ} \mathrm{C} \\
1,905^{\circ} \pm 20^{\circ} \mathrm{C} \\
1,845^{\circ} \pm 20^{\circ} \mathrm{C} \\
1,773.5^{\circ} \pm 1^{\circ} \mathrm{C}\end{array}$ \\
\hline
\end{tabular}

13 J. S. Acken, BS J. Research 12, 249 (1934) RP650.

14 W. F. Roeser, F. R. Caldwell, and H. T. Wensel, BS J. Research 6, 1119 (1931) RP326.

\section{RESULTS}

The results are summarized as follows:

\begin{tabular}{|c|c|c|c|c|c|c|c|}
\hline $\begin{array}{l}\text { Test } \\
\mathrm{Al}_{2} \mathrm{O}_{3} \\
\text { Pyrometer } \\
\text { Heating rate, }{ }^{\circ} \mathrm{C} / \mathrm{min} \\
\text { Meling point, }{ }^{\circ} \mathrm{C}\end{array}$ & $\begin{array}{c}1 \\
A \\
D \\
1 \\
2,000\end{array}$ & $\begin{array}{c}2 \\
C \\
D \\
1 \\
1,990\end{array}$ & $\begin{array}{l}\stackrel{3}{C} \\
D \\
5 \\
2,010\end{array}$ & $\begin{array}{l}\stackrel{4}{C} \\
\stackrel{E}{3} \\
2,000\end{array}$ & $\begin{array}{c}5 \\
A \\
E \\
1 \\
2,010\end{array}$ & $\begin{array}{c}6 \\
B \\
F \\
1.7 \\
1,997\end{array}$ & $\begin{array}{c}7 \\
B \\
F \\
2 \\
1,995\end{array}$ \\
\hline
\end{tabular}

The melting point was taken as the temperature at which the corners of the specimen were seen to become rounded. Heating slowly $(1 \% \mathrm{~min})$ during tests 1 and 5 beyond the temperature at which melting started caused an appreciable flow of the molten $\mathrm{Al}_{2} \mathrm{O}_{3}$ when the temperature reached $2,025^{\circ} \mathrm{C}$ and $2,035^{\circ} \mathrm{C}$, respectively.

$\mathrm{ThO}_{2}$ was selected for all of the parts making up the heating chamber because it is believed to have a very low vapor pressure at the temperatures attained in this work. Nevertheless, to determine if the alumina had been contaminated during the heating, the specimens from tests 1 and 2 were analyzed in the Spectroscopy Section of the National Bureau of Standards, and specimens from tests 6 and 7 were returned for quantitative spectrographic analysis to the concern which had supplied alumina $B$.

All the spectrographic analyses of the tested specimens indicated an appreciable "pickup" of impurities from the furnace atmosphere. This contamination was determined to be 1.1 percent of the top portion of the specimen and 1.0 percent of the bottom portion. It apparently was composed of about 0.5 silica and 0.3 magnesia, with nickel and iron making up the bulk of the remainder. The furnace parts shown in figure 1 had been used only for these melting-point tests of alumina, and consequently the contaminating oxides must have found their 
way as vapors into the heating chamber from the outer and relatively colder parts of the furnace.

It is possible that the contaminaton was concentrated in the outer portions of the specimens from aluminas $A$ and $B$, in which case it could have had a marked effect on the melting behavior, and the beginning of melting noted at $2,000^{\circ} \pm 10^{\circ} \mathrm{C}$ may have been the formation of a rather impure liquid at the surface. In support of this possibility, it was noted that specimens of alumina $C$, which were porous and therefore susceptible to contamination throughout the mass, melted sharply and uniformly, rather than beginning at the surface. Available information indicates that the two principal impurities, silica and magnesia, would lower the temperature at which melting would begin. Although the average value of $2,000^{\circ} \mathrm{C}$ obtained for the beginning of melting of the alumina used in the present investigation is considered accurate to \pm 10 degrees centigrade, the melting point of pure alumina may be slightly higher. However, it seems likely that the generally accepted value of $2,050^{\circ} \mathrm{C}$ is too high, and that a more correct value will be in the range $2,000^{\circ}$ to $2,030^{\circ} \mathrm{C}$.

\section{CONCLUSION}

As a result of the observations reported in this paper, it is believed that the melting point of alpha- $\mathrm{Al}_{2} \mathrm{O}_{3}$ is within the range $2,000^{\circ}$ to $2,030^{\circ} \mathrm{C}$, and that a more accurate determination of the true value must involve prevention of contamination of the alumina specimen by vapors of other elements in the furnace atmosphere.

Washington, February 23, 1945. 